\title{
Establishment of streptococci in the upper respiratory tract: longitudinal changes in the mouth and nasopharynx up to 2 years of age
}

\author{
E. KÖNÖNEN*‡, H. JOUSIMIES-SOMER*, A. BRYK*, T. KILPI† and M. KILIAN \\ * Departments of Microbiology and †Vaccines, National Public Health Institute, Helsinki, Finland and \\ $\$$ Department of Medical Microbiology \& Immunology, University of Aarhus, Aarhus, Denmark
}

\begin{abstract}
As part of a series of longitudinal studies on the development of the indigenous microflora of the upper respiratory tract, the establishment of streptococci in the oral cavity and nasopharynx and IgA1 protease production by the early streptococcal flora was examined in 50 healthy Caucasian infants at the ages of 2, 6, 12, 18 and 24 months. In the oral cavity, streptococci were found in all infants on every sampling occasion, Streptococcus mitis biovar 1 being the main finding in each age group. S. salivarius and $S$. mitis biovar 2 reached their highest prevalence during the first year of life, whereas the prevalence of $S$. oralis and $S$. sanguis showed no significant increase before 12 months of age. Salivary streptococci mainly consisted of the above-mentioned species during the follow-up period. In contrast to the oral cavity, no stable colonisation pattern was observed for viridans streptococci in the nasopharynx. $S$. mitis biovar 1 and $S$. pneumoniae, a traditional respiratory pathogen, were the principal streptococcal species among nasopharyngeal isolates. IgA1 protease production by early streptococci was common in infancy. Among the oral streptococcal microflora, $S$. mitis biovar 1 (especially during the first year of life) and $S$. oralis and $S$. sanguis constituted the main species responsible for this enzyme activity. In the nasopharynx, IgA1 protease was produced by $S$. mitis biovar $1, S$. oralis and $S$. pneumoniae. In conclusion, streptococcal colonisation differs in these two close habitats in the upper respiratory tract.
\end{abstract}

\section{Introduction}

The genus Streptococcus may be divided into six major clusters based on 16S rRNA gene sequencing: anginosus group, bovis group, mitis group, mutans group, pyogenic group and salivarius group. Each of these six groups contains several phylogenetically close species [1]. Viridans streptococci, including the anginosus, mitis, mutans and salivarius groups, are considered to be principal members of the indigenous microflora in the upper respiratory tract.

Viridans streptococci are the primary early colonisers in the oral cavity and are present during the first days of life $[2,3]$. Different reports on predentate infants

Received 15 Oct. 2001; revised version received 23 March 2002; accepted 30 March 2002.

Corresponding author: Dr E. Könönen. Present address: Department of Surgical Sciences, Faculty of Dentistry, Kuwait University, PO Box 24923, Safat 13110, Kuwait (e-mail: eija.kononen@hsc.kuniv.edu.kw). have suggested that Streptococcus salivarius, S. mitis biovar $1, S$. mitis biovar 2 or $S$. oralis are the predominant streptococcal species in infancy [2-5]. Soon after teeth erupt, S. sanguis $[4,6,7]$ and, later, mutans streptococci [8], become established in the mouth. Recent studies on the development of the early microflora $[9,10]$ indicate that the acquisition and succession of different bacterial species in the oral cavity is a selective process in terms of the age at which infants are susceptible to colonisation. In this respect, only fragmentary longitudinal data on oral streptococci $[2-4,6,7]$ and no data on the streptococcal colonisation pattern in the nasopharynx appear to exist in the literature.

The nasopharyngeal microflora has mainly been examined as the reservoir of potential respiratory pathogens. Indeed, except for $S$. pneumoniae (pneumococcus) limited data exist on the colonisation of other streptococcal species in the nasopharynx, although $\alpha$ haemolytic streptococci are frequently mentioned as primary inhabitants of the pharyngeal microflora and 
play an important role in interfering with the establishment of respiratory pathogens $[11,12]$. The current information on nasopharyngeal colonisation is not clear, because of unspecified sampling site (nasopharynx or oropharynx) and lack of detailed identification of the streptococci isolated.

Bacterial adherence to mucosal surfaces is the first step in the colonisation of the upper respiratory tract. Therefore, inhibition of adherence is the major mechanism in the host immune regulation of colonisation. The main protective antibody on mucosal surfaces of the upper respiratory tract is secretory immunoglobulin A (S-IgA). The subclass S-IgA1 dominates in oral and nasopharyngeal secretions as well as in maternal milk $[13,14]$. Interestingly, some viridans streptococci belonging to the mitis group are capable of producing $\operatorname{IgA} 1$ protease that specifically cleaves antibody molecules of the IgA1 subclass [15]. All strains of $S$. pneumoniae, $S$. oralis and $S$. sanguis produce this enzyme, whereas activity varies among populations of $S$. mitis biovar $1[16,17]$. Protease activity may aid the colonisation of streptococcal strains on mucosal surfaces despite the presence of IgA1. Interestingly, high numbers of streptococci that are capable of producing IgA1 protease have been reported to be present in infants' mouths $[18,19]$.

The aim of the present study was to examine the establishment of streptococci during the first 2 years of life in two habitats of the upper respiratory tract, i.e., the oral cavity and the nasopharynx, and the distribution of IgA1 protease-producing streptococci in relation to age.

\section{Material and methods}

\section{Subjects}

The study population consisted of 50 consecutive infants who were 2 months old at baseline (23 boys, 27 girls) and originated from a cohort of 329 healthy, full-term, Caucasian infants participating in the Finnish Otitis Media (FinOM) Cohort Study. The selection of the study infants has been presented in detail previously [9]. Before enrolment of the infants in the study, written informed consent was obtained from their parent(s). The study protocols were approved by the Ethical Issues' Committees of the National Public Health Institute, Department of Social and Health Care of Tampere City, and Tampere University Hospital.

\section{Bacterial sampling, culture and presumptive identification}

Unstimulated saliva was collected from the buccal sulcus area as described previously [9]. Nasopharyngeal samples were taken by inserting a flexible metalshaft swab with a calcium-alginate tip through the nasal cavity into the nasopharynx (the posterior part of the nasal cavity) and left in place for $5 \mathrm{~s}$. After withdrawal the swab shaft was cut and the tip was placed in VMGA III transport medium [20]. Specimens were sent via express mail to the Anaerobe Reference Laboratory of the National Public Health Institute, Helsinki, Finland, where they were processed within $24 \mathrm{~h}$ of collection. Samples were available from all 50 infants at 2 months ( \pm 2 weeks), 48 infants at 6 months ( \pm 2 weeks), 44 and 45 infants (salivary and nasopharyngeal samples, respectively) at 12 months ( \pm 4 weeks), 45 infants at 18 months ( \pm 4 weeks) and 42 infants at 24 months ( \pm 4 weeks) of age. Serially diluted samples were cultured on blood agar containing sheep blood 5\% and on chocolate agar for the growth of aerobic and facultative bacteria, on mitis salivarius agar containing bacitracin [21] for the selective isolation of mutans streptococci, and on crystal violet-nalidixic acid-gentamicin agar [22] for the selective isolation of $S$. pneumoniae. The plates were incubated in an aerobic atmosphere with $\mathrm{CO}_{2} 5 \%$ at $37^{\circ} \mathrm{C}$ for 2 days. A representative of each distinct colony type detected with a dissecting microscope was isolated and subcultured for presumptive identification, which included Gram's staining, determination of cell morphology, catalase reaction and haemolytic activity. Optochin disk test and commercial API 20 Strep test kits (bioMérieux, Marcy l'Etoile, France) were performed for $\alpha$-haemolytic and non-haemolytic, catalasenegative, gram-positive cocci. Lancefield serological groups were determined for $\beta$-haemolytic streptococci by the commercial Streptex rapid latex test (Murex Biotech, Dartford). All streptococcal isolates were frozen at $-70^{\circ} \mathrm{C}$ for further examination.

\section{Identification of viridans streptococcal isolates}

Further species identification of viridans streptococcal isolates was based on the scheme by Kilian et al. [15] combined with the scheme of Whiley and Beighton [23]. Subcultures of frozen stocks were made on blood agar for testing of hydrolysis of arginine and aesculin, production of acetoin (Voges-Proskauer test), alkaline phosphatase and $\beta$-N-acetylglucosaminidase with individual Rosco Diagnostic Tablets (Rosco, Taastrup, Denmark) and for testing of amygdalin, inulin, mannitol and sorbitol fermentation. Selected reactions were verified with broth media as described previously [15]. The type of haemolysis was confirmed on blood agar plates. To record the colonial morphology and the production of extracellular polysaccharides, subcultures were made on mitis salivarius agar incubated in an anaerobic atmosphere $\left(\mathrm{H}_{2} 5 \%, \mathrm{CO}_{2} 5 \%, \mathrm{~N}_{2} 90 \%\right)$ at $37^{\circ} \mathrm{C}$ for 2 days. The production of extracellular polysaccharides, noted as hard coherent colonies on mitis salivarius agar, was used as the key reaction for separation of $S$. oralis from IgA1 protease-producing $S$. mitis biovar 1 . 


\section{Testing of IgA1 protease production}

The streptococcal isolates were subcultured on ToddHewitt agar (Difco Laboratories, Detroit, MI, USA) for testing IgA1 protease production as described previously [17]. Briefly, a loopful of bacteria from a 24-h subculture was suspended in $40 \mu \mathrm{l}$ of IgA1 solution and incubated overnight at $37^{\circ} \mathrm{C}$. IgA1 degradation was revealed by immuno-electrophoresis.

\section{Results}

A total of 1265 clinical isolates identified as viridans streptococci and 12 reference strains ( $S$. sanguis SK-1, $S$. oralis SK-2 and SK-23, S. gordonii SK-3, S. mutans SK-28, S. anginosus SK-52, S. constellatus SK-53, S. intermedius SK-54, S. salivarius SK-56, S. mitis SK142, S. vestibularis SK-227 and S. crista SK-231) [15] were examined.
The mitis group dominated among the early streptococcal populations of the upper respiratory tract in the infants examined (Table 1). The division of the salivary and nasopharyngeal isolates into different streptococcal species and their proportions at each age group revealed that $S$. mitis biovar 1 dominated among the salivary isolates on all five sampling occasions and among the nasopharyngeal isolates on the first two sampling occasions (Table 2). In addition to S. mitis biovar $1, S$. pneumoniae and $S$. oralis also constituted a large proportion of the nasopharyngeal isolates on the last three and two sampling occasions, respectively. Of 1265 viridans streptococcal isolates tested, $53(4.2 \%)$ isolates remained unidentified. Four separate groups were distinguished among 44 unidentified isolates according to their similar phenotypic profile (data not shown).

The prevalence rates of the five most frequently encountered streptococcal taxa in saliva by 2 years of

Table 1. Prevalence of streptococcal groups in the saliva and nasopharynx of 50 infants during the first 2 years of life

\begin{tabular}{|c|c|c|c|c|c|c|c|c|c|c|}
\hline \multirow[b]{3}{*}{ Streptococcal group } & \multicolumn{10}{|c|}{ Percentage of infants with group at } \\
\hline & \multicolumn{2}{|c|}{$\begin{array}{l}2 \text { months } \\
(\mathrm{n}=50)^{*}\end{array}$} & \multicolumn{2}{|c|}{$\begin{array}{l}6 \text { months } \\
(\mathrm{n}=48)^{*}\end{array}$} & \multicolumn{2}{|c|}{$\begin{array}{c}12 \text { months } \\
(\mathrm{n}=44 / 45)^{*}\end{array}$} & \multicolumn{2}{|c|}{$\begin{array}{l}18 \text { months } \\
(\mathrm{n}=45)^{*}\end{array}$} & \multicolumn{2}{|c|}{$\begin{array}{l}24 \text { months } \\
(\mathrm{n}=42)^{*}\end{array}$} \\
\hline & $\mathrm{S}$ & NP & $\mathrm{S}$ & NP & $\mathrm{S}$ & NP & $\mathrm{S}$ & NP & $\mathrm{S}$ & NP \\
\hline Mitis & 98 & 24 & 100 & 60 & 100 & 53 & 100 & 51 & 100 & 38 \\
\hline Salivarius & 46 & 4 & 69 & 10 & 70 & 11 & 44 & 18 & 60 & 2 \\
\hline Anginosus & 2 & 4 & 0 & 0 & 2 & 0 & 0 & 0 & 0 & 0 \\
\hline Mutans & 0 & 0 & 0 & 0 & 2 & 0 & 7 & 0 & 5 & 0 \\
\hline Pyogenic $^{\dagger}$ & 0 & 2 & 0 & 4 & 0 & 4 & 0 & 2 & 0 & 0 \\
\hline
\end{tabular}

$\mathrm{S}$, saliva; NP, nasopharynx.

* Number of infants sampled.

${ }^{\dagger}$ Includes Lancefield group B and G streptococci (group A not detected).

Table 2. Distribution of streptococcal species within the saliva and nasopharynx of 50 infants on five sampling occasions during the first 2 years of life

\begin{tabular}{|c|c|c|c|c|c|c|c|c|c|c|}
\hline \multirow[b]{3}{*}{$\begin{array}{l}\text { Streptococcal } \\
\text { group/species }\end{array}$} & \multicolumn{10}{|c|}{ Percentage of isolates at } \\
\hline & \multicolumn{2}{|c|}{2 months } & \multicolumn{2}{|c|}{6 months } & \multicolumn{2}{|c|}{12 months } & \multicolumn{2}{|c|}{18 months } & \multicolumn{2}{|c|}{24 months } \\
\hline & $\begin{array}{c}\mathrm{S} \\
(\mathrm{n}=171)\end{array}$ & $\begin{array}{c}\text { NP } \\
(\mathrm{n}=21)\end{array}$ & $\begin{array}{c}\mathrm{S} \\
(\mathrm{n}=189)\end{array}$ & $\begin{array}{c}\text { NP } \\
(n=63)\end{array}$ & $\begin{array}{c}\mathrm{S} \\
(\mathrm{n}=202)\end{array}$ & $\begin{array}{c}\text { NP } \\
(n=36)\end{array}$ & $\begin{array}{c}\mathrm{S} \\
(\mathrm{n}=218)\end{array}$ & $\begin{array}{c}\text { NP } \\
(n=61)\end{array}$ & $\begin{array}{c}\mathrm{S} \\
(\mathrm{n}=343)\end{array}$ & $\begin{array}{c}\text { NP } \\
(n=27)\end{array}$ \\
\hline \multicolumn{11}{|l|}{ Mitis group } \\
\hline S. mitis 1 & 63.7 & 38.1 & 52.9 & 54.0 & 46.0 & 30.6 & 39.4 & 24.6 & 38.8 & 14.8 \\
\hline S. mitis 2 & 11.1 & 9.5 & 15.3 & 4.8 & 9.4 & 5.6 & 8.3 & 9.8 & 3.5 & 7.4 \\
\hline S. oralis & 2.9 & 0 & 2.6 & 4.8 & 6.9 & 5.6 & 18.3 & 18.0 & 16.3 & 33.3 \\
\hline S. sanguis & 0 & 0 & 1.1 & 0 & 7.9 & 2.8 & 10.1 & 1.6 & 17.2 & 0 \\
\hline S. crista & 1.2 & 0 & 0 & 0 & 4.5 & 0 & 2.3 & 0 & 0.9 & 0 \\
\hline S. gordonii & 0.6 & 0 & 0 & 0 & 2.0 & 0 & 2.3 & 0 & 0.3 & 0 \\
\hline S. parasanguis & 1.8 & 0 & 1.1 & 0 & 0 & 2.8 & 0.9 & 0 & 0 & 0 \\
\hline S. pneumoniae & 0.6 & 19.0 & 0.5 & 14.3 & 0.5 & 33.3 & 0.9 & 24.6 & 1.5 & 37.0 \\
\hline \multicolumn{11}{|l|}{ Salivarius group } \\
\hline S. salivarius & 13.5 & 9.5 & 18.0 & 4.8 & 15.3 & 11.1 & 11.9 & 14.8 & 13.7 & 3.7 \\
\hline S. vestibularis & 2.3 & 0 & 5.8 & 1.6 & 3.5 & 2.8 & 1.4 & 0 & 1.5 & 0 \\
\hline Anginosus group & 0.6 & 10.0 & 0 & 0 & 0.5 & 0 & 0 & 0 & 0 & 0 \\
\hline Mutans group & 0 & 0 & 0 & 0 & 1.5 & 0 & 0.5 & 0 & 0.9 & 0 \\
\hline Pyogenic group & 0 & 4.8 & 0 & 3.2 & 0 & 5.6 & 0 & 1.6 & 0 & 0 \\
\hline Unidentified isolates & 1.8 & 9.5 & 2.6 & 12.7 & 2.0 & 0 & 3.7 & 4.9 & 5.5 & 3.7 \\
\hline
\end{tabular}

S, saliva; NP, nasopharynx. 
age, i.e., S. mitis biovar 1, S. mitis biovar 2, S. salivarius, $S$. oralis and $S$. sanguis, are shown in Fig. 1. The infants were predentate at 2 months, predentate or dentate at 6 months and dentate at 12 months onwards. S. mitis biovar 1 was by far the most frequent finding in each age group, being present in the saliva of nearly all infants at each of the five sampling times. $S$. salivarius and $S$. mitis biovar 2 reached their highest prevalence during the first year of life, whereas $S$. oralis and $S$. sanguis showed no significant increase before 12 months of age. Other streptococci had much lower prevalence rates: $S$. vestibularis was found in $c$. $10 \%$ of the infants from 2 months onwards and $S$. crista from 12 months onwards. S. gordonii, $S$. parasanguis, the anginosus group and mutans streptococci were rarely detected in saliva during the first 2 years of life. S. pneumoniae was occasionally isolated from saliva during the follow-up period (Table 2).

Viridans streptococci were isolated from the nasopharyngeal samples relatively frequently, the collective prevalence rates varying between $22 \%$ and $56 \%$ on different sampling occasions. The prevalence rates of the five streptococcal taxa most frequently isolated from the nasopharynx by 2 years of age, i.e., $S$. mitis biovar 1, S. mitis biovar 2, S. salivarius, $S$. oralis and S. pneumoniae, are shown in Fig. 2. Except for $S$. mitis biovar 1, the prevalence rates of other viridans streptococci remained $<20 \%$ during the follow-up period. S. pneumoniae was the most prevalent streptococcal species after 6 months of age, the prevalence increasing steadily from $8 \%$ at 2 months to $33 \%$ at 18 months, then decreasing to $24 \%$ at 24 months (Fig. 2). One infant had a positive $S$. pneumoniae finding in the nasopharynx on every sampling occasion, but in most cases this species - like other streptococcal species was found on one occasion only.

Streptococci positive for IgA1 protease were frequently isolated from the upper respiratory tract during early childhood (Table 3). At 2 years, all children harboured IgA1 protease-positive streptococci in their saliva. Due to increasing frequencies of $S$. oralis and $S$. sanguis in the oral cavity with advanced age, more than half of the salivary streptococcal microflora was composed of strains of IgA1 protease-positive streptococci during the second year of life, although $S$. mitis biovar 1 constituted the main streptococcal species responsible for this enzyme activity (Table 3). Within salivary S. mitis biovar 1 populations, the proportion of IgA1 protease-positive isolates increased with age, being $55 \%$ at 2 and 6 months, $58 \%$ at 12 months, $66 \%$ at 18 months and $69 \%$ at 24 months. In most infants, either IgA1 protease-positive or simultaneously both $\operatorname{IgA} 1$ protease-positive and IgA1 protease-non-producing $S$. mitis biovar 1 strains were isolated from saliva. In the nasopharynx, $S$. pneumoniae and $S$. mitis biovar 1 were the main IgA1 protease-positive streptococcal species during the first year of life and, in addition to them, $S$. oralis during the second year of life (Table 3). Strains of IgA1 protease-positive streptococci dominated in the nasopharynx from the age of 6 months onwards.

\section{Discussion}

In this longitudinal study, where both predentate and dentate infants were examined, saliva was chosen as an oral specimen, which reflects the streptococcal microflora shedding from different oral surfaces. Another

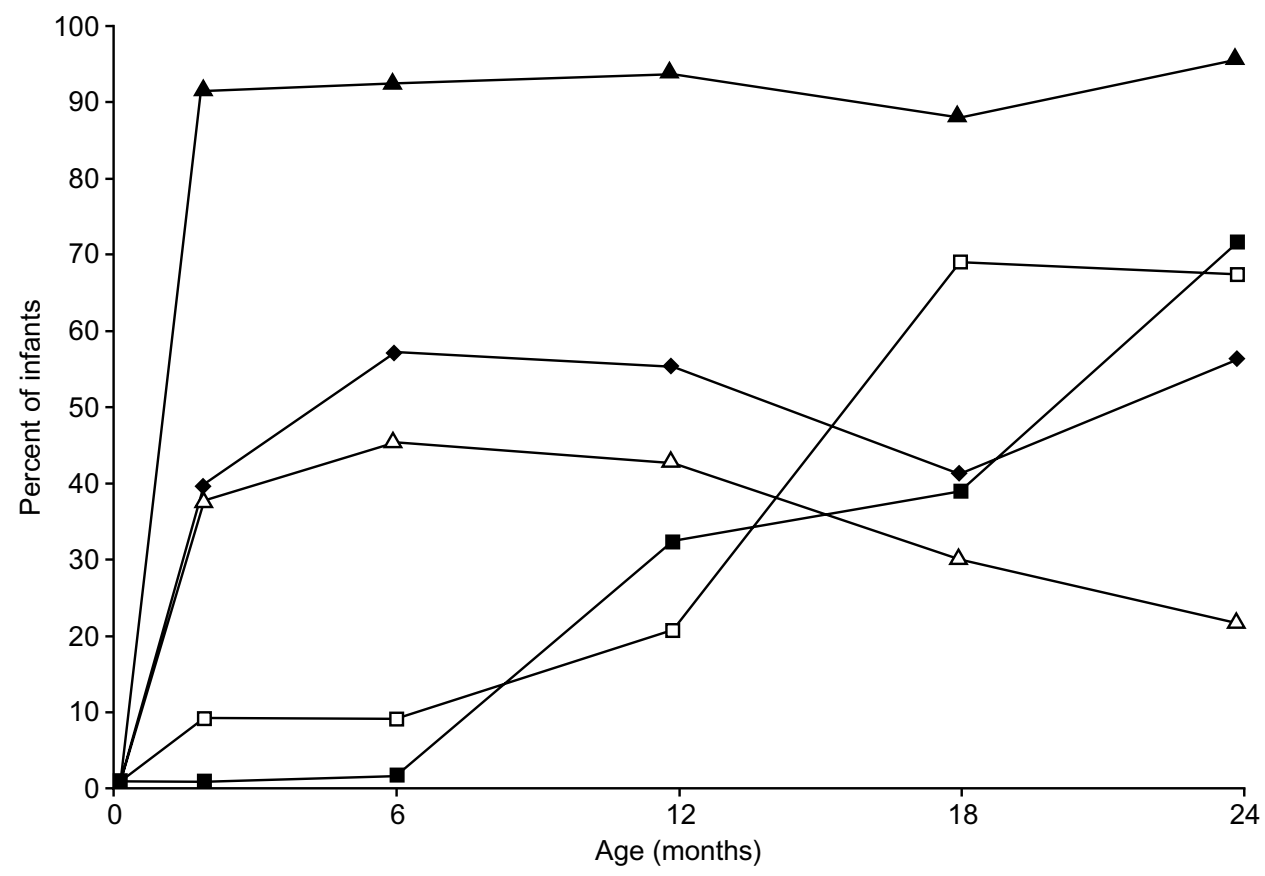

Fig. 1. Prevalence (\%) of infants with $S$. mitis biovar $1(\mathbf{\Delta})$, S. mitis biovar $2(\triangle)$, S. oralis $(\square)$, S. salivarius (ם) in saliva at 2, 6, 12, 18 and 24 months of age. 


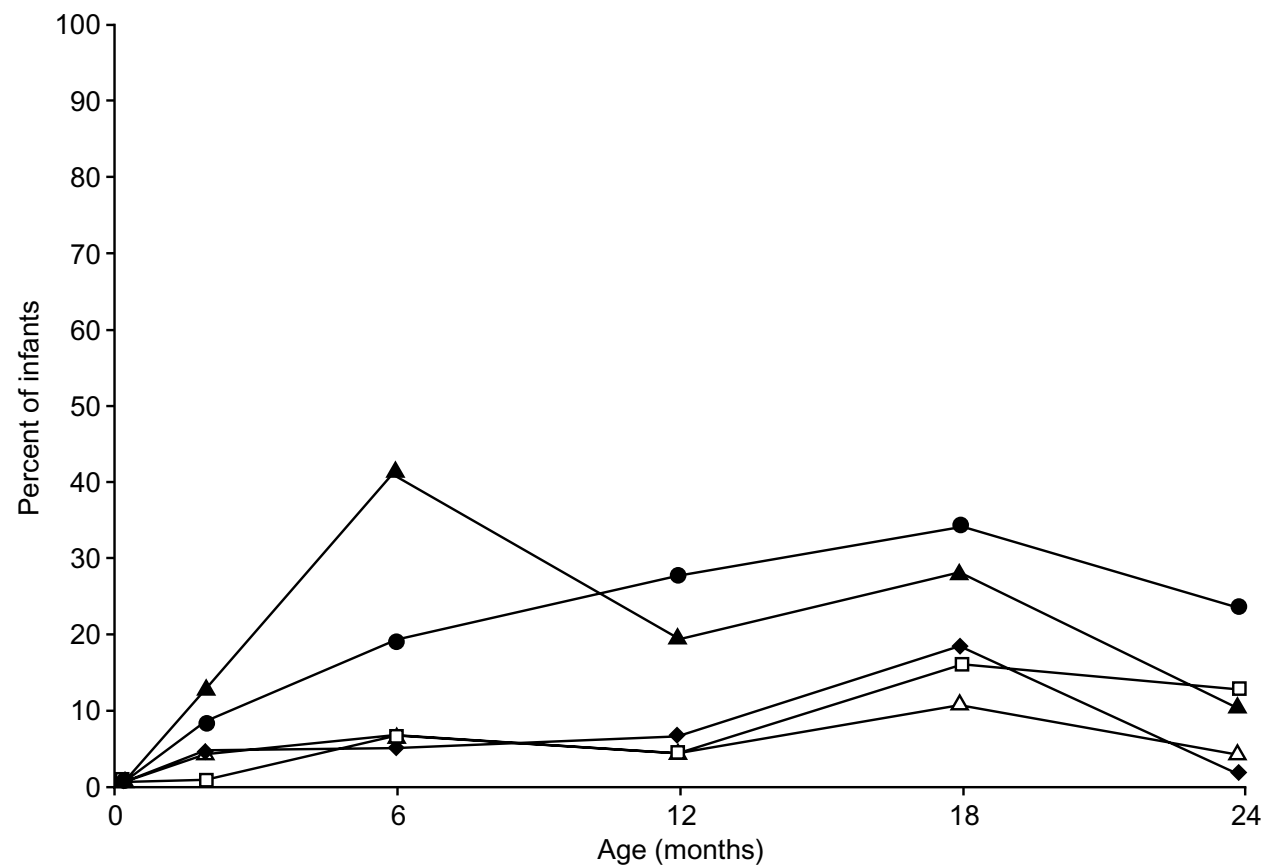

Fig. 2. Prevalence (\%) of infants with $S$. mitis biovar $1(\mathbf{\Delta})$, S. mitis biovar $2(\triangle)$, S. oralis $(\square)$, S. salivarius $(\bullet)$ and $S$. pneumoniae (O) in the nasopharynx at 2, 6, 12, 18 and 24 months of age.

Table 3. IgA1 protease production by streptococci isolated from the saliva or nasopharynx of infants at five scheduled follow-ups

\begin{tabular}{|c|c|c|c|c|c|c|c|}
\hline \multirow[b]{2}{*}{$\begin{array}{l}\text { Age } \\
\text { (months) }\end{array}$} & \multirow{2}{*}{$\begin{array}{c}\text { Number }(\%) \text { of } \\
\text { infants with } \\
\text { IgA1pr }^{+} \text {streptococci }\end{array}$} & \multirow[b]{2}{*}{ 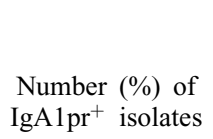 } & \multicolumn{5}{|c|}{ Proportion of indicated species among $\operatorname{IgA} 1 \mathrm{pr}^{+}$isolates } \\
\hline & & & S. mitis 1 & S. oralis & S. sanguis & S. pneumoniae & $\begin{array}{c}\text { Unidentified } \\
\text { species }\end{array}$ \\
\hline \multicolumn{8}{|l|}{ Saliva } \\
\hline 2 & $38 / 50(76)$ & $71 / 171(41.5)$ & $87.3 \%$ & $7.0 \%$ & 0 & $1.4 \%$ & $4.2 \%$ \\
\hline 6 & $38 / 48(79)$ & $67 / 189(35.4)$ & $82.1 \%$ & $7.5 \%$ & $3.0 \%$ & $1.5 \%$ & $6.0 \%$ \\
\hline 12 & $40 / 44(91)$ & $84 / 202(41.6)$ & $63.1 \%$ & $16.7 \%$ & $19.0 \%$ & $1.2 \%$ & 0 \\
\hline 18 & $42 / 45(93)$ & $129 / 218(59.2)$ & $45.0 \%$ & $31.0 \%$ & $17.1 \%$ & $1.6 \%$ & $5.4 \%$ \\
\hline 24 & $42 / 42(100)$ & $221 / 343(64.4)$ & $41.6 \%$ & $25.3 \%$ & $26.7 \%$ & $2.3 \%$ & $4.1 \%$ \\
\hline \multicolumn{8}{|c|}{ Nasopharynx } \\
\hline 2 & $8 / 50(16)$ & $8 / 21(38.1)$ & $25.0 \%$ & 0 & 0 & $50.0 \%$ & $25.0 \%$ \\
\hline 6 & $28 / 48(58)$ & $45 / 63(71.4)$ & $55.6 \%$ & $6.7 \%$ & 0 & $20.0 \%$ & $17.8 \%$ \\
\hline 12 & $20 / 45$ (44) & $22 / 36(61.1)$ & $31.8 \%$ & $9.1 \%$ & $4.5 \%$ & $54.5 \%$ & 0 \\
\hline 18 & $23 / 45(51)$ & $35 / 61(57.4)$ & $57.4 \%$ & $31.4 \%$ & $2.9 \%$ & $42.9 \%$ & $2.9 \%$ \\
\hline 24 & $18 / 42(43)$ & $24 / 27(88.9)$ & $16.7 \%$ & $37.5 \%$ & 0 & $41.7 \%$ & $4.2 \%$ \\
\hline
\end{tabular}

IgA1pr ${ }^{+}$, IgA1 protease-positive.

aspect of choosing saliva was its potential role as a transmission vehicle for bacteria between the two study habitats of the upper respiratory tract. Nasopharyngeal samples were collected through the nasal cavity, thus avoiding streptococcal contamination from the oral cavity. Streptococcal isolates were selected with a dissecting microscope on the basis of their colony morphology. This practice may lead to failure to isolate all streptococcal species present in samples. However, the results of the present study are comparable with previous studies [3-5] where a similar isolation technique was used for oral streptococci.

The precise species identification of viridans streptococci is tedious; the main difficulties encountered in the present study were with the mitis group. As in previous studies of oral streptococci in infancy [3, 4], attempts to identify the streptococcal isolates left a small proportion (4.2\%) unidentified. Most unidentified isolates formed various groups with similar profiles, indicating that considerable heterogeneity exists among streptococcal populations of the upper respiratory tract in infancy. This observation may be due to the presence of unrecognised species or may reflect a high degree of recombination between native clones and species among streptococcal populations in the immature mouth. Indeed, Kawamura et al. [24] described two further species in Japanese infants to be included in the mitis group, namely $S$. infantis and $S$. peroris. These two species can be separated from $S$. mitis biovar 1 only by sequence analysis of $16 \mathrm{~S}$ rRNA genes. Some heterogeneity also exists among arginine-hydrolysing $S$. mitis biovar 2 populations $[15,25]$. Recently, a novel arginine-positive oral streptococcus isolated from 
Australian infants, $S$. australis, has been added to the mitis group [26]. An arginine-positive $S$. mitis-like group was observed in the present study; however, it remained unidentified because of the production of IgA1 protease. At present it is not known whether S. australis produces this enzyme.

Viridans streptococci become established in the mouth soon after birth; Carlsson et al. [2] detected $S$. salivarius from the oral cavity in $75 \%$ of infants studied from the second day of life onwards. According to Pearce et al. [3], the streptococcal isolates from oral mucosal surfaces in infants during the first 3 days comprised mainly $S$. oralis, but 2 and 4 weeks later $S$. salivarius, $S$. mitis biovar 1 and $S$. oralis accounted equally for c. $90 \%$ of the total streptococcal microflora. Previous reports on high isolation rates of $S$. oralis from saliva and the oral mucosa in predentate infants [3-5] differ from the present study, in which $S$. oralis showed a somewhat similar colonisation pattern to $S$. sanguis. The nearly ubiquitous presence of $S$. mitis biovar 1 in the infants studied here corroborates well with similar findings by Smith et al. [4]; however, the prevalence of $S$. mitis biovar 2 in predentate infants was higher in the present study. In contrast, the crosssectional data produced by Tappuni and Challacombe [5] on predentate and dentate infants reported $S$. mitis biovar 2 as the main streptococcal finding in saliva. As identification schemes vary regarding biochemical reactions and nomenclature, discrepancies between studies are expected. Lucas et al. [27] found that the oral streptococcal microflora was fairly stable at species level and $S$. salivarius, $S$. oralis and $S$. mitis were the predominant species in repeated oral rinse samples from school-age children. The results of the present study demonstrate the predominance of these species at a young age. The relatively high prevalence of $S$. parasanguis reported by Lucas et al. [27] and the low prevalence in the present study suggest that this species colonises the oral cavity in later childhood rather than infancy.

Early studies by Carlsson et al. [2,6] pointed out the significance of an amenable ecological environment for oral streptococcal colonisation. They used repeated sampling to demonstrate how the eruption of teeth subsequently resulted in the establishment of $S$. sanguis in infants' mouths [6]. Recently, Caufield et al. confirmed this connection and suggested a discrete 'window of infectivity' at a median age of 9 months for $S$. sanguis [7], as previously shown for $S$. mutans at a median age of 26 months [8]. The results of the present study are in agreement with these findings based on culture. By using a checkerboard DNA probe assay for identification of target bacteria in samples from teeth and tongue, Tanner et al. [28] frequently detected $S$. mutans in children under 18 months of age and suggested that the tongue serves as a reservoir for many tooth-associated species. The high prevalence rate of $S$. mutans was probably due to a specific population investigated in terms of high caries incidence [28]. Frandsen et al. [29] examined the ecology of viridans streptococci in detail and demonstrated that each streptococcal species associated with specific oral/ oropharyngeal surfaces. $S$. mitis biovar 1 was isolated from most mucosal surfaces sampled, $S$. mitis biovar 2 and $S$. salivarius from the tongue surface, $S$. sanguis from buccal mucosae and initial dental plaque, and $S$. oralis from initial dental plaque, whereas the anginosus group dominated in subgingival plaque [29]. These findings may explain the failure of the present study to detect the latter group in infants.

The source and acquisition of the indigenous nasopharyngeal microflora and the succession of colonising species with age are poorly understood. The composition of the indigenous microflora in a certain niche may influence the outcome of colonisation of pathogens. The nasopharynx is considered to be the main reservoir for frequently encountered respiratory pathogens, particularly S. pneumoniae [30]. Aniansson et al. [31] reported various bacterial recoveries from nasopharyngeal cultures in an unselected sample of Swedish infants that were similar to the preliminary results of studies in Finnish infants [32]. The prevalence rates of $S$. pneumoniae in Swedish infants were similar to the present results but much lower for $\alpha$-haemolytic streptococci, i.e., $13 \%$ at $1-3$ months versus $22 \%$ at 2 months, $16 \%$ at $4-7$ months versus $56 \%$ at 6 months, $20 \%$ at $8-12$ months versus $36 \%$ at 12 months, and $20 \%$ versus $42 \%$ at 18 months, respectively. Except for $S$. pneumoniae, the mitis group streptococci have been considered as members of the non-pathogenic flora of the mouth and nasopharynx. Indeed, $\alpha$-haemolytic streptococci isolated from human pharynx have been the target of several studies in terms of their interference with respiratory pathogens $[11,12,33-$ 35]. On the other hand, potentially virulent $S$. mitis isolates have been detected in association with respiratory diseases [36]. In the present study, both viridans streptococcal species and $S$. pneumoniae were detected on only one or two sampling occasions during the follow-up. This observation indicates that the streptococcal colonisation pattern of infants' nasopharynges differs from that of infants' mouths.

It has often remained unclear in the literature as to whether investigators were studying the oropharynx or nasopharynx. Obviously, the oropharynx constitutes a mixed environment where both oral and nasopharyngeal species can be present. Rasmussen et al. [37] investigated the aerobic microflora of the nasal cavity in 10 healthy adults and stated that no single streptococcal species was a frequent inhabitant at this body site and demonstrated a clear difference between the bacterial composition of the nasal cavity and that of oropharynx. In the present study, nasopharyngeal samples were collected through the nasal cavity, thus contamination by streptococci within the mouth was excluded. Despite the previous observation of the 
absence of $S$. oralis in the posterior wall of the oropharynx [29], this species was a relatively frequent finding in nasopharyngeal samples collected from infants during the second year of life, when the prevalence of $S$. oralis increased significantly in the oral cavity.

The antigenic variation and capability of producing IgA1 protease may favour the successful early establishment of $S$. mitis biovar 1, which was by far the most prominent species capable of cleaving $\operatorname{IgA} 1$ during the first 2 years of life, and other IgA1 protease-positive streptococcal species on mucosal surfaces in the upper respiratory tract. IgA1 antibodies are the main mediators of specific immunity relevant to mucosal surfaces of the upper respiratory tract, although salivary concentrations of S-IgA are low in infancy [13]. Both factors conceivably facilitate the early colonisation of mucosal surfaces by this particular streptococcal species. This hypothesis is supported by the observation that initial dental plaque is dominated by $S$. mitis biovar $1, S$. oralis and $S$. sanguis, all of which are capable of IgA1 protease production $[29,38]$. Similarly, the most prevalent streptococcal species detected in the nasopharynx, $S$. pneumoniae, $S$. mitis biovar 1 (the main proportion of isolates were IgA1 protease-positive) and S. oralis, are IgA1 protease producers. The presence of strains capable of $\operatorname{IgA} 1$ protease production may even facilitate the colonisation of $\operatorname{IgA} 1$ protease-non-producing strains in the same micro-environment. In the present study strains of IgA1 protease-positive and IgA1 non-protease-producing $S$. mitis biovar 1 were isolated simultaneously from saliva of infants, thus confirming the observed heterogeneity within $S$. mitis biovar 1 populations colonising an immature mouth $[39,40]$. It has been suggested that increased proportions of IgA1 protease-positive streptococci on the oropharyngeal mucosa may jeopardise the local immune barrier and allow potential allergens to penetrate mucosal surfaces in the presence of this enzyme [41]. On the other hand, young infants can mount a specific secretory immune response against antigenic stimulation by IgA1 protease-positive streptococci [19].

The results of the present study indicate that despite the close proximity of the oral cavity and the nasopharynx, separate streptococcal colonisation patterns develop in the different parts of the upper respiratory tract during infancy. Early indigenous species, such as streptococci, may facilitate or inhibit the later establishment of pathogens at each body site. In this respect, the potential interplay of certain viridans streptococci with the host and other colonising bacteria of the upper respiratory tract is of specific interest to future research activity.

The clinical monitoring of infants by Ritva Syrjänen, MD, and by the study nurses Marja-Leena Hotti, Mervi Martola and Päivi Tervonen, and the technical assistance of Sirkku Waarala in cultivation and Mia
Kotkavuori in presumptive identification are gratefully acknowledged. This study was supported by grants from the Finnish Cultural Foundation, the Finnish Dental Society and the Nordic Foundation for Advanced Research (NorFA) to E.K.

\section{References}

1. Kawamura Y, Hou X-G, Sultana F, Miura H, Ezaki T Determination of 16S rRNA sequences of Streptococcus mitis and Streptococcus gordonii and phylogenetic relationships among members of the genus Streptococcus. Int $J$ Syst Bacteriol 1995; 45: 406-408.

2. Carlsson J, Grahnén H, Jonsson G, Wikner S. Early establishment of Streptococcus salivarius in the mouths of infants. J Dent Res 1970; 49: 415-418.

3. Pearce C, Bowden GH, Evans M et al. Identification of pioneer viridans streptococci in the oral cavity of human neonates. $J$ Med Microbiol 1995; 42: 67-72.

4. Smith DJ, Anderson JM, King WF, van Houte J, Taubman MA. Oral streptococcal colonization of infants. Oral Microbiol Immunol 1993; 8: 1-4.

5. Tappuni AR, Challacombe SJ. Distribution and isolation frequency of eight streptococcal species in saliva from predentate and dentate children and adults. J Dent Res 1993; 72: $31-36$.

6. Carlsson J, Grahnén H, Jonsson G, Wikner S. Establishment of Streptococcus sanguis in the mouths of infants. Arch Oral Biol 1970; 15: 1143-1148.

7. Caufield PW, Dasanayake AP, Li Y, Pan Y, Hsu J, Hardin JM. Natural history of Streptococcus sanguis in the oral cavity of infants: evidence for a discrete window of infectivity. Infect Immun 2000; 68: 4018-4023.

8. Caufield PW, Cutter GR, Dasanayake AP. Initial acquisition of mutans streptococci by infants: evidence for a discrete window of infectivity. J Dent Res 1993; 72: 37-45.

9. Könönen E, Kanervo A, Takala A, Asikainen S, JousimiesSomer H. Establishment of oral anaerobes during the first year of life. J Dent Res 1999; 78: 1634-1639.

10. Sarkonen N, Könönen E, Summanen P, Kanervo A, Takala A, Jousimies-Somer H. Oral colonization with Actinomyces species in infants by two years of age. J Dent Res 2000; 79: 864-867.

11. Sprunt K, Redman W. Evidence suggesting importance of role of interbacterial inhibition in maintaining balance of normal flora. Ann Intern Med 1968; 68: 579-590.

12. Roos K, Håkansson EG, Holm S. Effect of recolonisation with 'interfering' $\alpha$ streptococci on recurrences of acute and secretory otitis media in children: randomised placebo controlled trial. BMJ 2000; 322: 210-212.

13. Fitzsimmons SP, Evans MK, Pearce CL, Sheridan MJ, Wientzen R, Cole MF. Immunoglobulin A subclasses in infants' saliva and in saliva and milk from their mothers. $J$ Pediatr 1994; 124: 566-573.

14. Kirkeby L, Rasmussen TT, Reinholdt J, Kilian M. Immunoglobulins in nasal secretions of healthy humans: predominance of secretory immunoglobulin A1 (IgA1) and occurrence of neutralizing antibodies to $\operatorname{IgA} 1$ proteases of nasal bacteria. Clin Diagn Lab Immunol 2000; 7: 31-39.

15. Kilian M, Mikkelsen L, Henrichsen J. Taxonomic study of viridans streptococci: description of Streptococcus gordonii sp. nov. and emended descriptions of Streptococcus sanguis (White and Niven 1946), Streptococcus oralis (Bridge and Sneath 1982), and Streptococcus mitis (Andrewes and Horder 1906). Int J Syst Bacteriol 1989; 39: 471-484.

16. Kilian M, Mestecky J, Schrohenloher RE. Pathogenic species of the genus Haemophilus and Streptococcus pneumoniae produce immunoglobulin A1 protease. Infect Immun 1979; 26: $143-149$.

17. Reinholdt J, Tomana M, Mortensen SB, Kilian M. Molecular aspects of immunoglobulin A1 degradation by oral streptococci. Infect Immun 1990; 58: 1186-1194.

18. Cole MF, Evans M, Fitzsimmons S et al. Pioneer oral streptococci produce immunoglobulin A1 protease. Infect Immun 1994; 62: 2165-2168.

19. Smith DJ, King WF, Gilbert JV, Taubman MA. Structural integrity of infant salivary immunoglobulin A (IgA) in IgA1 protease-rich environments. Oral Microbiol Immunol 1998; 13: 89-96. 
20. Dahlén G, Pipattanagovit P, Rosling B, Möller ÅJR. A comparison of two transport media for saliva and subgingival samples. Oral Microbiol Immunol 1993; 8: 375-382.

21. Gold OG, Jordan HV, van Houte J. A selective medium for Streptococcus mutans. Arch Oral Biol 1973; 18: 1357-1364.

22. Nichols T, Freeman R. A new selective medium for Streptococcus pneumoniae. J Clin Pathol 1980; 33: 770-773.

23. Whiley RA, Beighton D. Current classification of the oral streptococci. Mini-review. Oral Microbiol Immunol 1998; 13. $195-216$.

24. Kawamura Y, Hou X-G, Todome Y et al. Streptococcus peroris sp. nov. and Streptococcus infantis sp. nov., new members of the Streptococcus mitis group, isolated from human clinical specimens. Int J Syst Bacteriol 1998; 48: 921-927.

25. Vandamme P, Torck U, Falsen E, Pot B, Goossens H, Kersters $\mathrm{K}$. Whole-cell protein electrophoretic analysis of viridans streptococci: evidence for heterogeneity among Streptococcus mitis biovars. Int J Syst Bacteriol 1998; 48: 117-125.

26. Willcox MDP, Zhu H, Knox KW. Streptococcus australis sp. nov., a novel oral streptococcus. Int J Syst Evol Microbiol 2001; 51: 1277-1281.

27. Lucas VS, Beighton D, Roberts GJ. Composition of the oral streptococcal flora in healthy children. $J$ Dent $2000 ; 28$ : 45-50.

28. Tanner ACR, Milgrom PM, Kent $\mathrm{R}$ et al. The microbiota of young children from tooth and tongue samples. J Dent Res 2002; 81: 53-57.

29. Frandsen EVG, Pedrazzoli V, Kilian M. Ecology of viridans streptococci in the oral cavity and pharynx. Oral Microbiol Immunol 1991; 6: 129-133.

30. Faden H, Duffy L, Wasielewski R et al. Relationship between nasopharyngeal colonization and the development of otitis media in children. $J$ Infect Dis 1997; 175: 1440-1445.

31. Aniansson G, Alm B, Andersson B et al. Nasopharyngeal colonization during the first year of life. J Infect Dis 1992; 165
(Suppl 1): S38-S42.

32. Könönen E, Kotkavuori M, Bryk A, Takala A, JousimiesSomer H. Changes in the nasopharyngeal microflora of infants as related to age, health and acute otitis media. In: Abstracts of the 8th International Congress on Infectious Diseases, Boston, MA, 1998: 282 (abstract 89.005).

33. Holm E, Grahn E. Bacterial interference in streptococcal tonsillitis. Scand J Infect Dis 1983; Suppl 39: 73-78.

34. Faden H, Stanievich J, Brodsky L, Bernstein J, Ogra PL. Changes in nasopharyngeal flora during otitis media of childhood. Pediatr Infect Dis J 1990; 9: 623-626.

35. Brook I. Bacterial interference in upper respiratory tract infections. Rev Med Microbiol 1999; 10: 225-233.

36. Whatmore AM, Efstratiou A, Pickerill AP et al. Genetic relationships between clinical isolates of Streptococcus pneumoniae, Streptococcus oralis, and Streptococcus mitis: characterization of "atypical" pneumococci and organisms allied to S. mitis harboring $S$. pneumoniae virulence factor-encoding genes. Infect Immun 2000; 68: 1374-1382.

37. Rasmussen TT, Kirkeby LP, Poulsen K, Reinholdt J, Kilian M. Resident aerobic microbiota of the adult human nasal cavity. APMIS 2000; 108: 663-675.

38. Kilian M, Reinholdt J, Nyvad B, Frandsen EVG, Mikkelsen L. IgA1 proteases of oral streptococci: ecological aspects. Immunol Invest 1989; 18: 161-170.

39. Hohwy J, Kilian M. Clonal diversity of the Streptococcus mitis biovar 1 population in the human oral cavity and pharynx. Oral Microbiol Immunol 1995; 10: 19-25.

40. Fitzsimmons S, Evans M, Pearce C et al. Clonal diversity of Streptococcus mitis biovar 1 isolates from the oral cavity of human neonates. Clin Diagn Lab Immunol 1996; 3: 517-522.

41. Kilian M, Husby S, Host A, Halken S. Increased proportions of bacteria capable of cleaving IgA1 in the pharynx of infants with atopic disease. Pediatr Res 1995; 38: 182-186. 